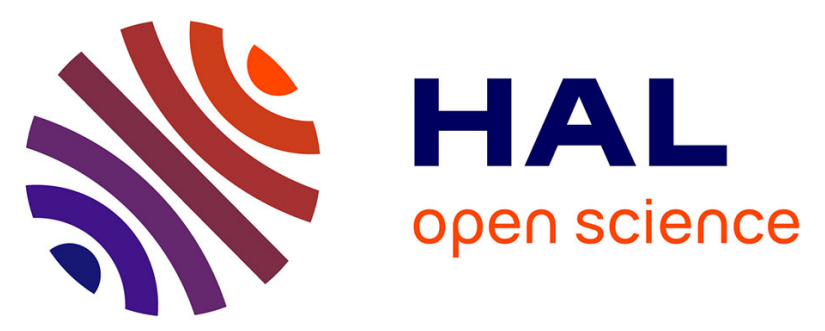

\title{
Genomic analysis of the Bacillus megaterium Mes11: New insights into nitroreductase genes associated with the degradation of mesotrione
}

Louis Carles, Florence Donnadieu, Ivan Wawrzyniak, Pascale Besse-Hoggan, Isabelle Batisson

\section{To cite this version:}

Louis Carles, Florence Donnadieu, Ivan Wawrzyniak, Pascale Besse-Hoggan, Isabelle Batisson. Genomic analysis of the Bacillus megaterium Mes11: New insights into nitroreductase genes associated with the degradation of mesotrione. International Biodeterioration \& Biodegradation, 2021, 162, pp.105254. 10.1016/j.ibiod.2021.105254 . hal-03268521v1

\section{HAL Id: hal-03268521 \\ https://hal.science/hal-03268521v1}

Submitted on 23 Jun 2021 (v1), last revised 27 Oct 2021 (v2)

HAL is a multi-disciplinary open access archive for the deposit and dissemination of scientific research documents, whether they are published or not. The documents may come from teaching and research institutions in France or abroad, or from public or private research centers.
L'archive ouverte pluridisciplinaire HAL, est destinée au dépôt et à la diffusion de documents scientifiques de niveau recherche, publiés ou non, émanant des établissements d'enseignement et de recherche français ou étrangers, des laboratoires publics ou privés. 


\section{Genomic analysis of the Bacillus megaterium Mes11: new insights into nitroreductase genes associated with the degradation of mesotrione.}

Louis Carles $^{\mathrm{a}, \mathrm{b}, \#}$, Florence Donnadieu ${ }^{\mathrm{a}}$, Ivan Wawrzyniak ${ }^{\mathrm{a}}$, Pascale Besse-Hoggan ${ }^{\mathrm{b}}$ and Isabelle Batisson $^{\text {a* }}$

a Université Clermont Auvergne, CNRS, Laboratoire Microorganismes : Génome et Environnement, F-63000 Clermont-Ferrand, France.

${ }^{\mathrm{b}}$ Université Clermont Auvergne, CNRS, Sigma Clermont, Institut de Chimie de ClermontFerrand, F-63000 Clermont-Ferrand, France.

\# now at: Department of Environmental Toxicology (Utox), Swiss Federal Institute of Aquatic Science and Technology (Eawag), Dübendorf, Switzerland.

e-mail address of each author:

louis.carles@eawag.ch

Florence.DONNADIEU@uca.fr

Ivan.WAWRZYNIAK@uca.fr

Pascale.BESSE@uca.fr

\section{Correspondence:}

Isabelle Batisson

e-mail: isabelle.batisson@uca.fr

Université Clermont Auvergne

Campus Universitaire des Cézeaux

1 Impasse Amélie Murat

TSA 60026 CS 60026

63178 AUBIERE Cedex

France 


\section{Highlights}

The complete genome of the Bacillus megaterium Mes11 was sequenced

The strain transformed mesotrione alone or in herbicide mixtures

The NfrA2 nitroreductase played a key physiological role in mesotrione transformation 


\begin{abstract}
Mesotrione is among the most recently marketed herbicides belonging to the triketone family and applied on maize crops. A Bacillus megaterium Mes11 strain isolated from an agricultural soil was able to completely transform $1 \mathrm{mM}$ of mesotrione, alone or in a mixture with $1 \mathrm{mM}$ of nicosulfuron and/or S-metolachlor herbicides, in $5 \mathrm{~h}$. Its complete genome contains one circular chromosome $(5,191,612 \mathrm{bp})$ and nine plasmids (from 45,372 to 169,684 bp). Genome analysis revealed that 10 genes encoded oxygen-insensitive nitroreductases of which only one (NfrA2) was shown to be involved in the first step of mesotrione transformation " in cellulo ». Indeed, quantitative reverse-transcription PCR analysis demonstrated that the NfrA2 expression was concomitant with mesotrione transformation, showing a maximum 6fold increase after a $4 \mathrm{~h}$ exposure to this single molecule. As opposed to nicosulfuron, the presence of S-metolachlor led to a significant 12 to 24-fold increase of NfrA2 expression after the same time of exposure, in the binary and ternary mixtures, respectively. These results highlight, for the first time, the physiological role of NfrA2 in mesotrione transformation « in cellulo $\gg$ and the environmental role of $B$. megaterium Mes 11 for bioremediation of mesotrionecontaminated ecosystems.
\end{abstract}

Keywords: Bacillus megaterium Mes11; complete genome sequence; herbicide degradation; mixtures; nitroreductases 


\section{Introduction}

Mesotrione (i.e. 2-(4-methylsulfonyl-2-nitrobenzoyl) cyclohexane-1,3-dione) is one of the new generation pesticides, chemically derived from a natural phytotoxin (leptospermone), and now becoming a major commercial herbicide (Casida and Durkin, 2017). Targeting a key enzyme involved in the plant carotenoid biosynthesis, the 4-hydroxyphenylpyruvate dioxygenase, by inhibition, its success was due not only to its high efficiency towards a wide range of broad-leaved and grass weeds, in particular those resistant to other herbicides, but also to its rather low recommended agronomic dose (applied at a rate of $150 \mathrm{~g}$ active ingredient ha ${ }^{1}$ ) conforming to the Integrated Pest Management (IPM), aiming to minimize pesticide use. It was also one of the first atrazine replacement herbicides, widely used worldwide (Mitchell et al., 2001). Belonging to the triketone family, mesotrione is a systemic post-emergence herbicide, typically used to protect maize crops.

Mesotrione fate has already been extensively studied in various matrices such as soil, water and crops (Barchanska, 2012; Dumas et al., 2017). Highly soluble, with a $\mathrm{K}_{\mathrm{d}}$ value range from

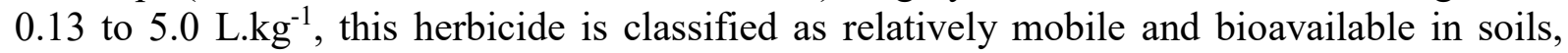
making biotransformation processes quite possible (Barchanska et al., 2016; Chaabane et al., 2008; Dyson et al., 2002; Gámiz et al., 2019).

The chemical mesotrione is distinguished by the presence of a nitro group on the benzoyl moiety. Indeed, a detailed analysis of the structure-activity relationships showed that an electron-withdrawing substituent at the 2-position was required for herbicidal activity, $-\mathrm{NO}_{2}$ being one of the strongest and mesotrione the most efficient herbicide compared to other triketone derivatives (Beaudegnies et al., 2009; Lee et al., 1998). Nevertheless, this nitro group also constitutes a potential site of attack for its (bio)degradation, by reduction into hydroxylamino and then amino group.

Various bacterial strains able to transform mesotrione have already been isolated (Dumas et al., 2017). Although several mesotrione metabolic pathways have been observed for a few of the isolated strains (Dobrzanski et al., 2018; Olchanheski et al., 2014; Pileggi et al., 2012; Romdhane et al., 2016), they are most frequently well conserved and common to the majority of mesotrione-transforming strains (Dumas et al., 2017). Not surprisingly, the major pathway generally involves reduction of the nitro group of mesotrione into intermediate free or cyclized hydroxylamino derivatives, these being subsequently transformed to the final metabolite, 2amino-4-methylsulfonylbenzoic acid (AMBA) after the hydrolysis of the $\beta$-diketone bond. AMBA then accumulates in the medium and has also been detected in the environment (Alferness and Wiebe, 2002; Dumas et al., 2017).

Type II and type I nitroreductases are the enzymes involved in such transformations of nitroaromatic compounds, such as mesotrione, by reduction via one or two-electron transfer, respectively (Bryant et al., 1981; Peterson et al., 1979). The type II nitroreductases, whose activity is oxygen-sensitive, catalyse the one-electron reduction of a substrate, using FMN or FAD as cofactor and forming a nitro anion radical. This radical undergoes futile cycling in the presence of oxygen giving super-oxide anions and regenerating the parent nitro-compound (Mason and Holtzman, 1975). The oxygen-insensitive type I nitroreductases are NAD(P)Hdependent, FMN binding proteins. These enzymes are responsible for catalytic reduction of the nitro group formally by addition of two electrons to give the nitroso intermediate. This, in turn is reduced further to hydroxylamino and amino intermediates accepting pairs of electrons from NAD(P)H (Bryant et al., 1981; Peterson et al., 1979). Therefore, nitroreductases are good candidates for bioremediation of nitroaromatic compounds and several enzymes have been characterized as able to degrade the toxic 2,4,6-trinitrotoluene (TNT) (Gumuscu and Tekinay, 2013; Hannink et al., 2001; Ramya Sree et al., 2019).

A Bacillus megaterium Mes11, among all the degrading-strains, was isolated from an agricultural soil and is able to completely and rapidly biotransform mesotrione in aerobic conditions (Batisson et al., 2009). The fact that nitroreductase is involved in this 
biotransformation by $B$. megaterium Mes11 was first evidenced by a network analysis of mesotrione-adaptative proteins which emphasizes a direct link with this type of enzyme (Bardot et al., 2015). More recently, Carles et al. (2016) confirmed that two oxygen-insensitive nitroreductases of the B. megaterium Mes11 strain, NfrA1 and NfrA2 (Genbank accession nos. KT008921 and KT008916), expressed in a heterologous E. coli system and purified, were involved in the first step of mesotrione transformation when exposed to this sole molecule.

To further investigate the role of nitroreductases in mesotrione transformation, a study of their « in cellulo » expression was carried out by sequencing and analysing the whole genome of the Bacillus megaterium Mes11. We also compiled an inventory of all the nitroreductasecoding genes potentially involved in mesotrione-transformation. Moreover, as mesotrione is usually applied agriculturally in mixture with the herbicides S-metolachlor (chloroacetanilide) and nicosulfuron (sulfonylurea) in order to improve its efficiency and the range of weeds treated, a focus was made on the impact of such mixtures on the nitroreductase expression. We have already shown that when mixed, any of these herbicides could have an impact on their individual toxicity and on the transformation kinetics of the others (Carles et al., 2018; Joly et al., 2013). In this manuscript, the physiological activity of the various nitroreductases found in B. megaterium to be involved in mesotrione-transformation was determined under multicontamination conditions to account for agricultural mixture exposure more realistically.

\section{Materials and Methods}

\subsection{Bacterium, chemicals and media}

Bacillus megaterium Mes11 was isolated from soil (Batisson et al., 2009). The analytical grade herbicides (Mesotrione, nicosulfuron, S-metolachlor (Pestanal) and the Tryptic Soy broth (TS) medium were purchased from Sigma Aldrich (France). The composition of Glucosemineral Salt Medium (GSM), pH 6.7, was previously reported by Carles et al. (2018).

\subsection{Whole genome sequencing of $B$. megaterium Mes 11 and annotation.}

Pac-Bio RS technology (GATC Biotech) was used to sequence the B. megaterium Mes11 genome. The draft genome was annotated using RAST version 4.0 (1) and the NCBI Prokaryotic Genomes Automatic Annotation Pipeline (PGAAP; http://www.ncbi.nlm.nih.gov/genomes/static/Pipeline.html).

The B. megaterium Mes11 genome sequences have been deposited in GenBank under accessing numbers: CP048883 to CP048892.

\subsection{Expression and purification of the plasmidic nitroreductase in E. coli}

The PCR amplification was carried out using the primers NRK forward (5'ATGAATAATACAATTGAATTACTTTCT-3') and NRK reverse (5'TTTTTTAGCAAACCCTTGTTTGTTTAA-3'). The amplicon was cloned into the expression vector $\mathrm{pEXP5-CT/TOPO} \mathrm{(Invitrogen).} \mathrm{The} \mathrm{protein} \mathrm{expression} \mathrm{and} \mathrm{mesotrione}$ biotransformation tests were carried out as described by Carles et al. (2016).

\subsection{Culture of B. megaterium Mes11 with herbicides}


Bacillus megaterium Mes11 was grown in $750 \mathrm{~mL}-\mathrm{TS}$ broth supplemented with $0.1 \mathrm{mM}$ mesotrione, under agitation $(150 \mathrm{rpm})$ at $28{ }^{\circ} \mathrm{C}$. After an overnight culture, the cells were centrifuged $\left(8,000 \mathrm{~g}, 5 \mathrm{~min}, 4{ }^{\circ} \mathrm{C}\right)$ and washed with a solution of $\mathrm{NaCl}(0.8 \%)$. The pellet was then resuspended in GSM $(150 \mathrm{~mL})$ supplemented with $1 \mathrm{mM}$ of mesotrione, nicosulfuron and S-metolachlor, either alone, in binary or ternary mixtures. Abiotic controls (medium without inoculation and inoculation without herbicide) were also realized. For each condition, the cultures were carried out in triplicate and incubated in the dark $\left(28^{\circ} \mathrm{C}, 150 \mathrm{rpm}\right)$. Samples $(1$ $\mathrm{mL}$ ) were regularly taken and centrifuged $(12,500 \mathrm{~g}, 5 \mathrm{~min})$. HPLC analyses were performed on the supernatants and total RNA was recovered from the corresponding pellets (see below). The herbicide biosorption was measured from a $1 \mathrm{~mL}$ culture pellet, stirred vigorously overnight in $500 \mu \mathrm{L}$ ethanol at room temperature before being centrifuged (12,500 g, $5 \mathrm{~min}$ ). The extraction process was repeated twice.

\subsection{Analysis of the herbicides and their metabolites}

The herbicide concentrations were measured by HPLC as described previously by Carles et al. (2018). The mesotrione metabolites were identified and quantified by LC-MS and ${ }^{1} \mathrm{H} \mathrm{NMR}$, respectively, as previously described by Carles et al. (2018).

\subsection{Reverse transcription- quantitative PCR (RT-qPCR) analysis}

Total RNA was extracted at T0, 2, 4 and $8 \mathrm{~h}$ as described by Dugat-Bony et al. (2011). The DNase treatments (twice) and reverse transcription were performed with the DNaseI kit (Ambion) and the SuperScript ${ }^{\mathrm{TM}}$ III Reverse Transcriptase kit (Invitrogen) using Random Primers (Invitrogen), respectively. The qPCR reactions were performed in a total reaction volume of $15 \mu \mathrm{L}$ containing $7.5 \mu \mathrm{L}$ of MESA GREEN qPCR MasterMix Plus for SYBR ${ }^{\circledR}$ Assay Low ROX kit (Eurogentec), $0.3 \mu \mathrm{M}$ of each primer and $1 \mu \mathrm{L}$ of $0.1 \mathrm{X}$ cDNA. The primers used for NfrA1 and NfrA2 nitroreductase genes amplification were reported by Carles et al. (2016). The qPCR was carried out in an Realplex2 epgradient S Mastercycler (Eppendorf) as follows: initial denaturation at $95{ }^{\circ} \mathrm{C}$ for $5 \mathrm{~min}, 40$ cycles of denaturation at $95{ }^{\circ} \mathrm{C}$ for $30 \mathrm{~s}$, primer annealing at $57{ }^{\circ} \mathrm{C}$ for $15 \mathrm{~s}$ and elongation at $72{ }^{\circ} \mathrm{C}$ for $20 \mathrm{~s}$. The $16 \mathrm{~S}$ rRNA gene was used to normalize the results using primers described by Borrel et al. (2012).

\subsection{Statistical analysis}

R (v3.5.0) and RStudio (v1.1.456) were used for statistical analyses. Differences in NfrA2 expression fold-change were assessed in triplicate experiments using two-way ANOVA followed by separate post hoc comparisons (Tukey's test, $\mathrm{P}<0.05$ ). The two-way ANOVA includes the factors treatment (mesotrione; mesotrione + nicosulfuron; mesotrione $+\mathrm{S}$ metolachlor; mesotrione + nicosulfuron + S-metolachlor $)$ and time $(0,2,4$ and $8 \mathrm{~h})$. The normality and homogeneity of variance were checked prior to ANOVA tests (Shapiro's and Levene's tests, respectively, for $\mathrm{P}<0.05)$.

\section{Results}

\subsection{Analysis of the B. megaterium genome}

The PacBio sequencing of the B. megaterium Mes 11 genome generated ca. 1,15 Gbp of nucleotides and the average subread length was $12,649 \mathrm{bp}$. A total of 90,915 reads were sequenced with an N50 of ca. $16.970 \mathrm{~kb}$. After the de novo assembly, 10 contigs were produced 
and the genome size of $B$. megaterium Mes11 was predicted to be $5.2 \mathrm{Mbp}$. It includes one chromosome and 9 plasmids (pBMG1 to pBMG9). Their general features are summarized in Fig. 1 and Table 1.

In our previous study, in silico analysis of the three available $B$. megaterium genomes highlighted 9 chromosome encoded oxygen-insensitive nitroreductase genes also detected in the Mes 11 genome (Carles et al., 2016; Genbank accession nos. KT008914 - KT008922). The analysis of the whole genome of $B$. megaterium Mes 11 also revealed an additional nitroreductase gene encoded by the pBMG7 plasmid (accession no. BMG_6397).

\subsection{Mesotrione transformation by B. megaterium Mes11}

The B. megaterium strain showed similar rapid mesotrione transformation kinetics whether used alone or in binary or ternary mixtures with other herbicides (nicosulfuron and Smetolachlor) (Fig. 2). A complete dissipation of the herbicide was observed within $5 \mathrm{~h}$ of culture, whereas none was noted without the strain (abiotic control). Concomitantly to the mesotrione dissipation, two transitory metabolites, the hydroxylamino derivative in equilibrium with its cyclized form isoxazolol, appeared after $2 \mathrm{~h}$ of incubation and reached their maximum concentration when there was no mesotrione left (Table 2). They were formed quantitatively by the reduction of the nitro group of mesotrione before being transformed into AMBA. Mass balance analyses showed that no loss of compound occurred during the mesotrione transformation since values ranged from $86 \%$ to $108 \%$ at the end of the experiment (Table 2). This is in agreement with the absence of significant mesotrione and metabolite adsorption observed on bacterial cells (data not shown). The two other herbicides, nicosulfuron and Smetolachlor, were not degraded during the $8 \mathrm{~h}$ of incubation monitored under these conditions.

\section{3. "In cellulo" expression of the mesotrione-transforming nitroreductase}

Since the newly-discovered plasmid encoded nitroreductase was unable to transform mesotrione after heterologous expression and purification, reverse transcription - quantitative PCR using the 16S rRNA gene for normalization (Borrel et al., 2012) was focused on the only two nitroreductases previously described to do it in vitro (Carles et al., 2016) in order to confirm their function " in cellulo » and in various multi-contamination contexts. Their transcription level was determined during mesotrione biodegradation by Bacillus megaterium Mes 11 .

The qPCR results showed no induction of the NfrA1 expression but an induction of NfrA2 by mesotrione in the $B$. megaterium Mes11, whatever the herbicide exposure conditions. No significant induction of its expression was observed when $B$. megaterium was exposed to nicosulfuron alone (data not shown). Conversely, in the presence of mesotrione, alone or with the other herbicides, the induction of NfrA2 expression was observed concomitantly to the dissipation of mesotrione (Fig. 2). In comparison to the control culture (without any herbicide), a NfrA2 expression was detected as soon as T0, showing similar values for all treatments (Table 2). It reached its maximum $4 \mathrm{~h}$ after induction before a decrease, probably due to the complete dissipation of mesotrione after $5 \mathrm{~h}$ of culture (Fig. 2 and Table 2).

An effect of time (taking all the treatments together), treatments (taking all the times together) and an interaction time*treatment for a given time (ANOVA, $\mathrm{P}<0.001$ ) was observed on NfrA2 expression level. Thus, compared to the value at T0, the six-fold expression obtained after $4 \mathrm{~h}$ of culture in the presence of mesotrione alone is unaffected by the addition of nicosulfuron.

At the same time, when S-metolachlor was present in the mixture, a greatly increased induction was, nevertheless, observed compared to the T0 expression (around 12 and 24 fold for binary and ternary mixtures, respectively), highlighting a two- to four-fold stimulation compared to mesotrione applied alone or with nicosulfuron. A slight stimulation of NfrA2 expression was also observed in the $B$. megaterium strain when the culture was exposed to the 
S-metolachlor alone (about 4-fold at $\mathrm{T} 4 \mathrm{~h}$ compared to the $\mathrm{T} 0$ expression) or in mixture with nicosulfuron (about 2.5 at $\mathrm{T} 8 \mathrm{~h}$ compared to the T0 expression) (data not shown). The upregulation of the $N f r A 2$ gene observed in the presence of S-metolachlor was synergized by the presence of mesotrione with a 5 fold and 8.5 fold increase of the NfrA 2 expression with binary and ternary herbicide mixtures, respectively.

\section{Discussion}

The genome analysis of Bacillus megaterium Mes11 revealed one circular chromosome and 9 indigenous plasmids (Fig. 1). The high number of plasmids of this strain is within the range of that already described for other Bacillus megaterium strains, harboring a highly variable number of plasmids, from zero (DSM319 strain; Stahl et Esser, 1983; Eppinger et al., 2011) to 10 (strain NTC-2; Wang et al., 2020). The GC \% of the B. megaterium Mes 11 plasmids, varying between 33.5 and $35.5 \%$, was lower than that of the chromosome (38.2\%) (Table 1). This is in agreement with other studies which also revealed a lower GC content for plasmids in several B. megaterium strains (Eppinger et al., 2011; Liu et al., 2011; Wang et al., 2020). Among the 4055 genes with predicted functions detected on the chromosome and the 520 genes harbored by the nine plasmids (Table 1), 9 and 1 oxygen-insensitive nitroreductase were detected, respectively. This plasmid-encoded nitroreductase blasted only with Bacillus genomes. Unless already detected in the chromosome of several Bacillus strains (e.g. B. subtilis (McIntyre et al., 2019), B. intestinalis (Xu et al., 2015), B. pumilus (Zhang et al., 2019)), this nitroreductase was only recently detected in the chromosome of a $B$. megaterium strain (strain Ni2-3; Cai et al., 2019) and on a plasmid of B. megaterium strain KNU-01 (Jo et al., unpublished).

Carles et al. (2016) tested the capacity of these nitroreductases to transform mesotrione in vitro under a wide range of experimental conditions $(\mathrm{pH}$, temperature, types of cofactor, concentration of the cofactor). This study showed that after heterologous expression and purification of the 9 chromosomic-encoded ones, only two of them (NfrA1 and NfrA2) were involved in the transformation of mesotrione. The plasmid encoded nitroreductase now highlighted by the analysis of the complete $B$. megaterium Mes11 genome was also tested for its capacity to transform mesotrione but not seen to do so for the various in vitro experimental conditions tested. Thus, among the 10 nitroreductases found in the genome of $B$. megaterium Mes11, we were only able to show the mesotrione-transformation capacity of the two chromosomic-encoded enzymes NfrA1 and NfrA2 in vitro in our experimental conditions.

Moreover, comparing between these two nitroreductases, we showed that NfrAl was not involved in the first step of mesotrione transformation "in cellulo" and that only NfrA2 played a key physiological role in $B$. megaterium Mes11. The mesotrione transformation kinetics by this strain and that of metabolite production (Table 2) were similar to those previously observed with purified nitroreductases (Carles et al., 2016).

Furthermore, a previous study has demonstrated the mesotrione transformation capacity of the B. megaterium Mes11 strain in a multi-contamination context (Carles et al., 2018). Our results corroborated this capacity "in cellulo". Indeed, we showed that the NfrA2 expression was strongly increased during the mesotrione transformation and even more in the presence of S-metolachlor coupled or not with nicosulfuron (Fig. 2 and Table 2). The 2 to 4 -fold NfrA2 overexpression when S-metolachlor is present compared to mesotrione alone could not only be attributed to its involvement in the mesotrione degradation since the mesotrione transformation kinetics was similar in all conditions tested. We could thus stipulate that the stimulation of the NfrA2 expression by S-metolachlor could also be explained by the induction of oxidative stress caused by this molecule which leads to its toxic effect for cells including lipid peroxidation and the excessive production of reactive oxygen species (ROS) (Martins et al., 2011; NykielSzymańska et al., 2019; Marchado and Soares, 2021). Defense mechanisms must be set up to protect the cells from oxidative stress. These responses involve specific enzymes such as 
disulfide reductase, superoxide dismutase, catalase or glutathione peroxidase. Nitroreductases were shown to also harbour these enzymatic activities (Bang et al., 2012; de Oliveira et al., 2009; Liochev et al., 1999; Mermod et al., 2010; Paterson et al., 2002; Streker et al., 2005; Tam et al., 2006), thus contributing to the cell defense by an up-regulation of the corresponding genes (Mostertz, 2004; Roldán et al., 2008). The higher NfrA2 expression in presence of the three herbicides studied could be explained by the synergistic action of the pesticides (Cedergreen, 2014; Carles et al., 2018). To our knowledge, this is the first time that the involvement of a nitroreductase has been demonstrated "in cellulo" during the degradation of a pesticide, also revealing the influence of other molecules on the nitroreductase physiological activity in a multi-contamination context.

Hence, our results provide new insight into the mesotrione transformation by Bacillus megaterium Mes11 strain and highlighted the key physiological role of the NfrA2 enzyme in this process. Nitroreductases being involved in reduction of various nitro-aromatic compounds such as pesticides and antibiotics (Caballero et al., 2005; Symons and Bruce, 2006; Roldán et al., 2008; Carles et al., 2016; El-Hossary et al., 2017; Green et al., 2019), these enzymes (or their genes) could be used as biomarkers to predict the capacity of ecosystems to transform such molecules.

\section{Conclusion}

In this study, we showed, for the first time, that the NfrA2 nitroreductase of Bacillus megaterium Mes 11 played a key physiological role in the mesotrione transformation and that it is still active in a realistic agricultural context of herbicide mixture exposure or even overexpressed. The Bacillus megaterium Mes11 could thus be used for mesotrione bioremediation and its active nitroreductase could have potential biotechnological applications in the environmental domain.

\section{Acknowledgement}

The authors acknowledge Philip Hoggan for English reviewing. This work was supported by the Agence Nationale de la Recherche [grant number ANR-13-CESA-0002 TRICETOX] (programme CESA), the Région Auvergne, the French Ministry for Higher Education and Research and the European Regional Development Fund.

\section{Declaration of interests}

The authors declare that they have no known competing financial interests or personal relationships that could have appeared to influence the work reported in this paper.

\section{References}

Alferness, P., Wiebe, L., 2002. Determination of Mesotrione Residues and Metabolites in Crops, Soil, and Water by Liquid Chromatography with Fluorescence Detection. J. Agric. Food Chem. 50, 3926-3934. https://doi.org/10.1021/jf011696y

Bang, S.Y., Kim, J.H., Lee, P.Y., Bae, K.-H., Lee, J.S., Kim, P.-S., Lee, D.H., Myung, P.K., Park, B.C., Park, S.G., 2012. Confirmation of Frm2 as a novel nitroreductase in Saccharomyces cerevisiae. Biochem. Biophys. Res. Commun. 423, 638-641. https://doi.org/10.1016/j.bbrc.2012.05.156

Barchańska, H., 2012. Triketones herbicides: expectations and risk, in: Advances in Chemistry Research. J. C. Taylor, pp. 243-264.

Barchanska, H., Kluza, A., Krajczewska, K., Maj, J., 2016. Degradation study of mesotrione and other triketone herbicides on soils and sediments. J. Soils Sediments 16, 125-133. https://doi.org/10.1007/s11368-015-1188-1 
Bardot, C., Besse-Hoggan, P., Carles, L., Le Gall, M., Clary, G., Chafey, P., Federici, C., Broussard, C., Batisson, I., 2015. How the edaphic Bacillus megaterium strain Mes11 adapts its metabolism to the herbicide mesotrione pressure. Environ. Pollut. 199, 198-208. https://doi.org/10.1016/j.envpol.2015.01.029

Batisson, I., Crouzet, O., Besse-Hoggan, P., Sancelme, M., Mangot, J.-F., Mallet, C., Bohatier, J., 2009. Isolation and characterization of mesotrione-degrading Bacillus sp. from soil. Environ. Pollut. 157, 1195-1201. https://doi.org/10.1016/j.envpol.2008.12.009

Beaudegnies, R., Edmunds, A.J.F., Fraser, T.E.M., Hall, R.G., Hawkes, T.R., Mitchell, G., Schaetzer, J., Wendeborn, S., Wibley, J., 2009. Herbicidal 4-hydroxyphenylpyruvate dioxygenase inhibitors-A review of the triketone chemistry story from a Syngenta perspective. Bioorg. Med. Chem. 17, 4134-4152. https://doi.org/10.1016/j.bmc.2009.03.015

Borrel, G., Lehours, A.-C., Crouzet, O., Jézéquel, D., Rockne, K., Kulczak, A., Duffaud, E., Joblin, K., Fonty, G., 2012. Stratification of Archaea in the Deep Sediments of a Freshwater Meromictic Lake: Vertical Shift from Methanogenic to Uncultured Archaeal Lineages. PLoS ONE 7, e43346. https://doi.org/10.1371/journal.pone.0043346

Bryant, D.W., McCalla, D.R., Leeksma, M., Laneuville, P., 1981. Type I nitroreductases of Escherichia coli. Can. J. Microbiol. 27, 81-86. https://doi.org/10.1139/m81-013

Caballero, A., Lazaro, J.J., Ramos, J.L., Esteve-Nunez, A., 2005. PnrA, a new nitroreductase-family enzyme in the TNT-degrading strain Pseudomonas putida JLR11. Environ. Microbiol. 7, 12111219. https://doi.org/10.1111/j.1462-2920.2005.00801.x

Cai, X., Zheng, X., Zhang, D., Iqbal, W., Liu, C., Yang, B., Zhao, X., Lu, X., Mao, Y., 2019. Microbial characterization of heavy metal resistant bacterial strains isolated from an electroplating wastewater treatment plant. Ecotoxicol. Environ. Saf. 181, 472-480. https://doi.org/10.1016/j.ecoenv.2019.06.036

Carles, L., Besse-Hoggan, P., Joly, M., Vigouroux, A., Moréra, S., Batisson, I., 2016. Functional and structural characterization of two Bacillus megaterium nitroreductases biotransforming the herbicide mesotrione. Biochem. J. 473, 1443-1453. https://doi.org/10.1042/BJ20151366

Carles, L., Joly, M., Bonnemoy, F., Leremboure, M., Donnadieu, F., Batisson, I., Besse-Hoggan, P., 2018. Biodegradation and toxicity of a maize herbicide mixture: mesotrione, nicosulfuron and $\mathrm{S}$ metolachlor. J. Hazard. Mater. 354, 42-53. https://doi.org/10.1016/j.jhazmat.2018.04.045

Casida, J.E., Durkin, K.A., 2017. Pesticide Chemical Research in Toxicology: Lessons from Nature. Chem. Res. Toxicol. 30, 94-104. https://doi.org/10.1021/acs.chemrestox.6b00303

Cedergreen, N., 2014. Quantifying Synergy: A Systematic Review of Mixture Toxicity Studies within $\begin{array}{lllll}\text { Environmental PLOS ONE } & \text { Toxicology. }\end{array}$ https://doi.org/10.1371/journal.pone.0096580

Chaabane, H., Vulliet, E., Calvayrac, C., Coste, C.-M., Cooper, J.-F., 2008. Behaviour of sulcotrione and mesotrione in two soils. Pest Manag. Sci. 64, 86-93. https://doi.org/10.1002/ps.1456

de Oliveira, I.M., Zanotto-Filho, A., Moreira, J.C.F., Bonatto, D., Henriques, J.A.P., 2009. The role of two putative nitroreductases, Frm2 $\mathrm{p}$ and $\mathrm{Hbn} 1 \mathrm{p}$, in the oxidative stress response in Saccharomyces cerevisiae. Yeast 27, 89-102. https://doi.org/10.1002/yea.1734

Dobrzanski, T., Gravina, F., Steckling, B., Olchanheski, L.R., Sprenger, R.F., Espírito Santo, B.C., Galvão, C.W., Reche, P.M., Prestes, R.A., Pileggi, S.A.V., Campos, F.R., Azevedo, R.A., Sadowsky, M.J., Beltrame, F.L., Pileggi, M., 2018. Bacillus megaterium strains derived from water and soil exhibit differential responses to the herbicide mesotrione. PLOS ONE 13, e0196166. https://doi.org/10.1371/journal.pone.0196166

Dumas, E., Giraudo, M., Goujon, E., Halma, M., Knhili, E., Stauffert, M., Batisson, I., Besse-Hoggan, P., Bohatier, J., Bouchard, P., Celle-Jeanton, H., Costa Gomes, M., Delbac, F., Forano, C., Goupil, P., Guix, N., Husson, P., Ledoigt, G., Mallet, C., Mousty, C., Prévot, V., Richard, C., Sarraute, S., 2017. Fate and ecotoxicological impact of new generation herbicides from the triketone family: An overview to assess the environmental risks. J. Hazard. Mater. 325, 136-156. https://doi.org/10.1016/j.jhazmat.2016.11.059

Dugat-Bony, E., Missaoui, M., Peyretaillade, E., Biderre-Petit, C., Bouzid, O., Gouinaud, C., Hill, D., Peyret, P., 2011. HiSpOD: probe design for functional DNA microarrays. Bioinformatics 27, 641-648. https://doi.org/10.1093/bioinformatics/btq712 
Dyson, J.S., Beulke, S., Brown, C.D., Lane, M.C.G., 2002. Adsorption and Degradation of the Weak Acid Mesotrione in Soil and Environmental Fate Implications. J. Environ. Qual. 31, 613-618. https://doi.org/10.2134/jeq2002.6130

El-Hossary, E.M., Förstner, K.U., François, P., Baud, D., Streker, K., Schrenzel, J., Ohlsen, K., Holzgrabe, U., 2017. A Novel Mechanism of Inactivating Antibacterial Nitro Compounds in the Human Pathogen Staphylococcus aureus by Overexpression of a NADH-Dependent Flavin Nitroreductase. Antimicrob. Agents Chemother. 62. https://doi.org/10.1128/AAC.01510-17

Eppinger, M., Bunk, B., Johns, M.A., Edirisinghe, J.N., Kutumbaka, K.K., Koenig, S.S.K., Huot Creasy, H., Rosovitz, M.J., Riley, D.R., Daugherty, S., Martin, M., Elbourne, L.D.H., Paulsen, I., Biedendieck, R., Braun, C., Grayburn, S., Dhingra, S., Lukyanchuk, V., Ball, B., Ul-Qamar, R., Seibel, J., Bremer, E., Jahn, D., Ravel, J., Vary, P.S., 2011. Genome Sequences of the Biotechnologically Important Bacillus megaterium Strains QM B1551 and DSM319. J. Bacteriol. 193, 4199-4213. https://doi.org/10.1128/JB.00449-11

Gámiz, B., Velarde, P., Spokas, K.A., Cox, L., 2019. Dynamic Effect of Fresh and Aged Biochar on the Behavior of the Herbicide Mesotrione in Soils. J. Agric. Food Chem. 67, 9450-9459. https://doi.org/10.1021/acs.jafc.9b02618

Green, K.D., Fosso, M.Y., Mayhoub, A.S., Garneau-Tsodikova, S., 2019. Investigating the promiscuity of the chloramphenicol nitroreductase from Haemophilus influenzae towards the reduction of 4nitrobenzene derivatives. Bioorg. Med. Chem. Lett. 29, 1127-1132. https://doi.org/10.1016/j.bmcl.2019.02.025

Gumuscu, B., Tekinay, T., 2013. Effective biodegradation of 2,4,6-trinitrotoluene using a novel bacterial strain isolated from TNT-contaminated soil. Int. Biodeterior. Biodegrad. 85, 35-41. https://doi.org/10.1016/j.ibiod.2013.06.007

Hannink, N., Rosser, S.J., French, C.E., Basran, A., Murray, J.A.H., Nicklin, S., Bruce, N.C., 2001. Phytodetoxification of TNT by transgenic plants expressing a bacterial nitroreductase. Nat. Biotechnol. 19, 1168-1172. https://doi.org/10.1038/nbt1201-1168

Jo, Y., Huy, P.Q., Shin, J.H., unpublished. Complete genome of Bacillus megaterium KNU-01.

Joly, P., Bonnemoy, F., Charvy, J.-C., Bohatier, J., Mallet, C., 2013. Toxicity assessment of the maize herbicides S-metolachlor, benoxacor, mesotrione and nicosulfuron, and their corresponding commercial formulations, alone and in mixtures, using the Microtox ${ }^{\circledR}$ test. Chemosphere 93, 2444-2450. https://doi.org/10.1016/j.chemosphere.2013.08.074

Lee, D.L., Knudsen, C.G., Michaely, W.J., Chin, H.-L., Nguyen, N.H., Carter, C.G., Cromartie, T.H., Lake, B.H., Shribbs, J.M., Fraser, T., 1998. The structure-activity relationships of the triketone class of HPPD herbicidest. Pestic. Sci. 54, 377-384. https://doi.org/10.1002/(SICI)10969063(199812)54:4<377::AID-PS827>3.0.CO;2-0

Liochev, S.I., Hausladen, A., Fridovich, I., 1999. Nitroreductase A is regulated as a member of the soxRS regulon of Escherichia coli. Proc. Natl. Acad. Sci. 96, 3537-3539. https://doi.org/10.1073/pnas.96.7.3537

Liu, L., Li, Y., Zhang, J., Zou, W., Zhou, Z., Liu, J., Li, X., Wang, L., Chen, J., 2011. Complete Genome Sequence of the Industrial Strain Bacillus megaterium WSH-002. J. Bacteriol. 193, 6389-6390. https://doi.org/10.1128/JB.06066-11

Machado, M.D., Soares, E.V., 2021. Exposure of the alga Pseudokirchneriella subcapitata to environmentally relevant concentrations of the herbicide metolachlor: Impact on the redox $\begin{array}{llll}\text { homeostasis. Ecotoxicol. Environ. } & \text { Saf. 207, }\end{array}$ https://doi.org/10.1016/j.ecoenv.2020.111264

Martins, P.F., Carvalho, G., Gratão, P.L., Dourado, M.N., Pileggi, M., Araújo, W.L., Azevedo, R.A., 2011. Effects of the herbicides acetochlor and metolachlor on antioxidant enzymes in soil bacteria. Process Biochem. 46, 1186-1195. https://doi.org/10.1016/j.procbio.2011.02.014

Mason, R.P., Holtzman, J.L., 1975. The role of catalytic superoxide formation in the O2 inhibition of nitroreductase. Biochem. Biophys. Res. Commun. 67, 1267-1274. https://doi.org/10.1016/0006-291X(75)90163-1

McIntyre, A.B.R., Alexander, N., Grigorev, K., Bezdan, D., Sichtig, H., Chiu, C.Y., Mason, C.E., 2019. Single-molecule sequencing detection of N6-methyladenine in microbial reference materials. Nat. Commun. 10, 579. https://doi.org/10.1038/s41467-019-08289-9 
Mermod, M., Mourlane, F., Waltersperger, S., Oberholzer, A.E., Baumann, U., Solioz, M., 2010. Structure and Function of CinD (YtjD) of Lactococcus lactis, a Copper-Induced Nitroreductase Involved in Defense against Oxidative Stress. J. Bacteriol. 192, 4172-4180. https://doi.org/10.1128/JB.00372-10

Mitchell, G., Bartlett, D.W., Fraser, T.E., Hawkes, T.R., Holt, D.C., Townson, J.K., Wichert, R.A., 2001. Mesotrione: a new selective herbicide for use in maize. Pest Manag. Sci. 57, 120-128. https://doi.org/10.1002/1526-4998(200102)57:2<120::AID-PS254>3.0.CO;2-E

Mostertz, J., Scharf, C., Hecker, M., Homuth, G., 2004. Transcriptome and proteome analysis of Bacillus subtilis gene expression in response to superoxide and peroxide stress. Microbiology 150, 497512. https://doi.org/10.1099/mic.0.26665-0

Nykiel-Szymańska, J., Różalska, S., Bernat, P., Słaba, M., 2019. Assessment of oxidative stress and phospholipids alterations in chloroacetanilides-degrading Trichoderma spp. Ecotoxicol. Environ. Saf. 184, 109629. https://doi.org/10.1016/j.ecoenv.2019.109629

Olchanheski, L.R., Dourado, M.N., Beltrame, F.L., Zielinski, A.A.F., Demiate, I.M., Pileggi, S.A.V., Azevedo, R.A., Sadowsky, M.J., Pileggi, M., 2014. Mechanisms of Tolerance and High Degradation Capacity of the Herbicide Mesotrione by Escherichia coli Strain DH5- $\alpha$. PLoS ONE 9, e99960. https://doi.org/10.1371/journal.pone.0099960

Paterson, E.S., Boucher, S.E., Lambert, I.B., 2002. Regulation of the nfsA Gene in Escherichia coli by SoxS. J. Bacteriol. 184, 51-58. https://doi.org/10.1128/JB.184.1.51-58.2002

Peterson, F., Mason, R., Hovsepian, J., Holtzman, J., 1979. Oxygen-sensitive and oxygen-insensitive nitroreduction by Escherichia-coli and rat hepatic microsomes. J. Biol. Chem. 254, 4009-4014.

Pileggi, M., Pileggi, S.A.V., Olchanheski, L.R., da Silva, P.A.G., Munoz Gonzalez, A.M., Koskinen, W.C., Barber, B., Sadowsky, M.J., 2012. Isolation of mesotrione-degrading bacteria from aquatic environments in Brazil. Chemosphere 86, 1127-1132. https://doi.org/10.1016/j.chemosphere.2011.12.041

Ramya Sree, B., Sowjanya, B., Divakar, K., 2019. Metagenomic bioprospecting of novel oxygen insensitive nitroreductase for degradation of nitro aromatic compounds. Int. Biodeterior. Biodegrad. 143, 104737. https://doi.org/10.1016/j.ibiod.2019.104737

Roldán, M.D., Pérez-Reinado, E., Castillo, F., Moreno-Vivián, C., 2008. Reduction of polynitroaromatic compounds: the bacterial nitroreductases. FEMS Microbiol. Rev. 32, 474-500. https://doi.org/10.1111/j.1574-6976.2008.00107.x

Romdhane, S., Devers-Lamrani, M., Martin-Laurent, F., Calvayrac, C., Rocaboy-Faquet, E., Riboul, D., Cooper, J.-F., Barthelmebs, L., 2016. Isolation and characterization of Bradyrhizobium sp. SR1 degrading two $\beta$-triketone herbicides. Environ. Sci. Pollut. Res. 23, 4138-4148. https://doi.org/10.1007/s11356-015-4544-1

Stahl, U., Esser, K., 1983. Plasmid heterogeneity in various strains of Bacillus megaterium. Eur. J. Appl. Microbiol. Biotechnol. 17, 248-251. https://doi.org/10.1007/BF00510424

Streker, K., Freiberg, C., Labischinski, H., Hacker, J., Ohlsen, K., 2005. Staphylococcus aureus NfrA (SA0367) Is a Flavin Mononucleotide-Dependent NADPH Oxidase Involved in Oxidative Stress Response. J. Bacteriol. 187, 2249-2256. https://doi.org/10.1128/JB.187.7.2249-2256.2005

Symons, Z.C., Bruce, N.C., 2006. Bacterial pathways for degradation of nitroaromatics. Nat. Prod. Rep. 23, 845. https://doi.org/10.1039/b502796a

Tam, L.T., Antelmann, H., Eymann, C., Albrecht, D., Bernhardt, J., Hecker, M., 2006. Proteome signatures for stress and starvation inBacillus subtilis as revealed by a 2-D gel image color coding approach. Proteomics 6, 4565-4585. https://doi.org/10.1002/pmic.200600100

Wang, B., Zhang, D., Chu, S., Zhi, Y., Liu, X., Zhou, P., 2020. Genomic Analysis of Bacillus megaterium NCT-2 Reveals Its Genetic Basis for the Bioremediation of Secondary Salinization Soil. Int. J. Genomics 2020, 1-11. https://doi.org/10.1155/2020/4109186

Xu, S., Boitano, M., Clark, T.A., Vincze, T., Fomenkov, A., Kumar, S., Too, P.H.-M., Gonchar, D., Degtyarev, S.K., Roberts, R.J., 2015. Complete Genome Sequence Analysis of Bacillus subtilis T30. Genome Announc. 3, e00395-15. https://doi.org/10.1128/genomeA.00395-15

Zhang, Z., Yin, L., Li, X., Zhang, C., Zou, H., Liu, C., Wu, Z., 2019. Analyses of the Complete Genome Sequence of the Strain Bacillus pumilus ZB201701 Isolated from Rhizosphere Soil of Maize 
650

651

652

653

654

655

656

657

658

659

660

661

662

663

664

under Drought and Salt Stress. Microbes Environ. 34, 310-315. https://doi.org/10.1264/jsme2.ME18096

\section{Figure captions:}

Fig. 1. Circular genome map of Bacillus megaterium Mes11. From the innermost to the outermost circle : the inner black circle shows the scale line in Mbps ; circles (1) and (2) represent the $\mathrm{G}+\mathrm{C}$ content and $\mathrm{G}+\mathrm{C}$ skew; circles (3) and (4) represent the predicted coding sequences on the forward and backward strands, colored by the COG functional categories.

Fig. 2. Biotransformation kinetics of mesotrione, alone or in mixtures, by B. megaterium Mes 11 and NfrA2 expression fold-change compared to a control culture without mesotrione. The values are the mean \pm standard errors $(n=3)$ of experimental data. Statistical differences were indicated between the four conditions at each time by lowercase letters (Tukey's test; $a<b, P$ $<0.05$ ) and between each time and T0 (ANOVA, $* \mathrm{P}<0.001$ ). Meso: mesotrione; Nico: nicosulfuron; S-meto: S-metolachlor.

Table 1: General features of Bacillus megaterium Mes11 genome.

Table 2: Concentration of metabolites produced during the mesotrione $(1 \mathrm{mM})$ degradation by B. megaterium Mes11 and fold change in NrfA2 expression. Values are expressed as means (n $=3) \pm$ standard error. 

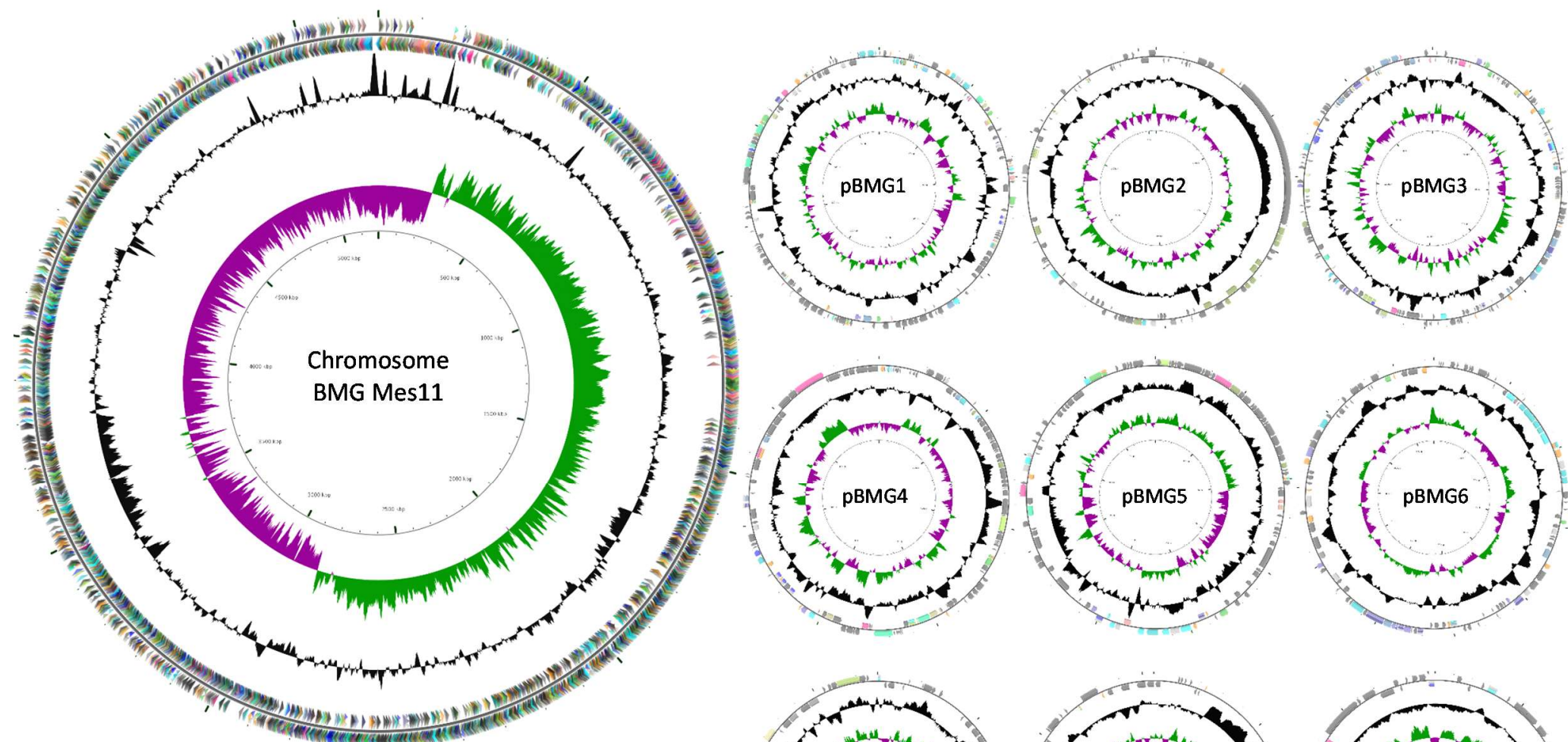

RNA processing and modification

1. Chromatin structure and dynamics

Translation, ribosomal structure and biogenesis

Transcription

- Replication, recombination and repair

Cell cycle control, cell division, chromosome partitioning

Posttranslational modification, protein turnover, chaperones
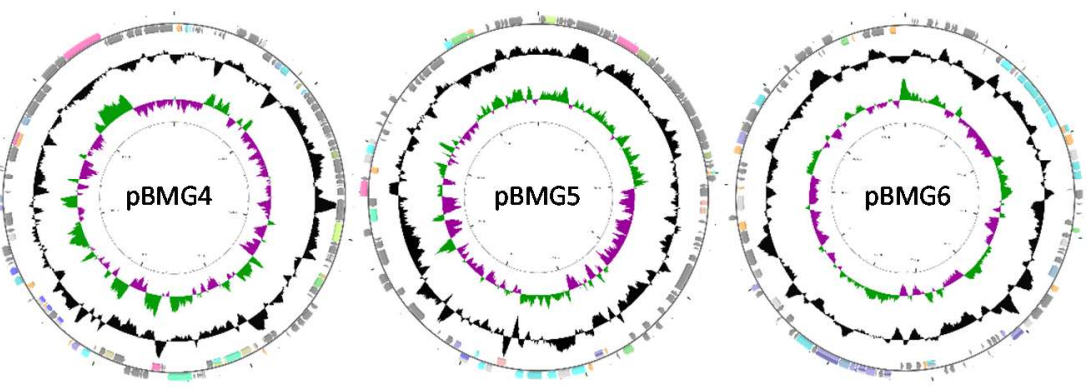

Cell wall/membrane/envelope biogenesis

Cell motility

Inorganic ion transport and metabolism

Lipid transport and metabolism

Intracellular trafficking, secretion, and vesicular transport

Defense mechanisms

Extracellular structures

Nuclear structure
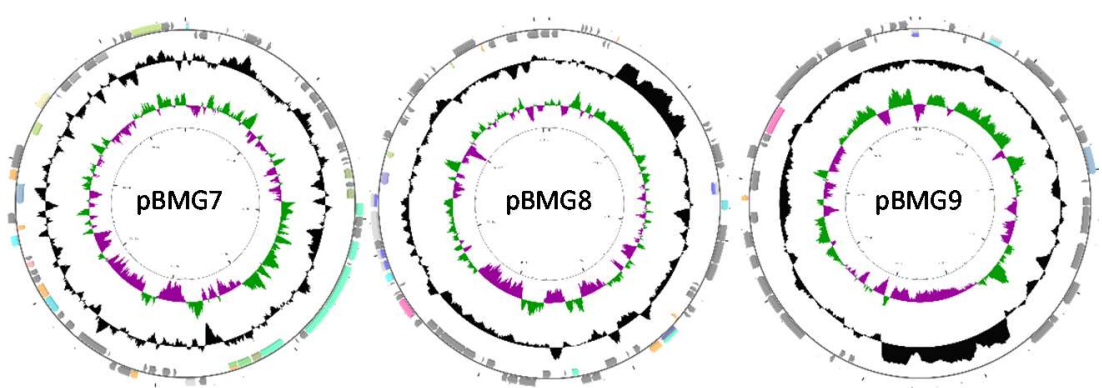

Cytoskeleton

Energy production and conversion

Carbohydrate transport and metabolism

Amino acid transport and metabolism

Nucleotide transport

- Coenzyme transport and metabolism

- Lipid transport and metabolism
Secondary metabolites biosynthesis, transport and catabolism General function prediction only

- Function unknown

E No assigned COG

- GC content

GC skew+ 
667
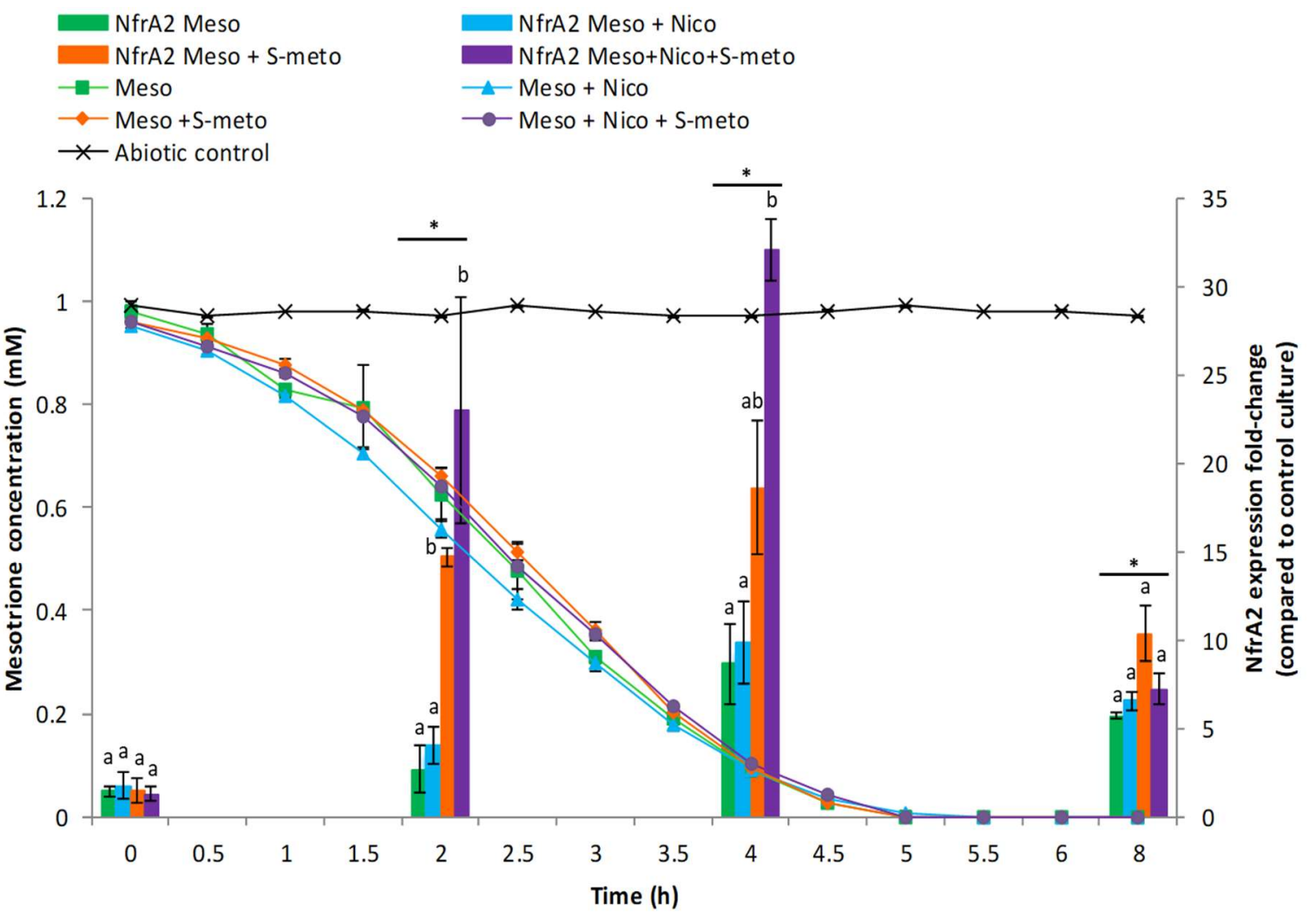
Table 1: General features of Bacillus megaterium Mes11 genome.

\begin{tabular}{|c|c|c|c|c|c|c|}
\hline Features & $\begin{array}{c}\text { Genomic } \\
\text { size (bp) }\end{array}$ & $\begin{array}{c}\text { CG content } \\
(\%)\end{array}$ & $\begin{array}{c}\text { Total } \\
\text { genes }\end{array}$ & $\begin{array}{c}\text { Genes with } \\
\text { predicted } \\
\text { functions }\end{array}$ & $\begin{array}{c}\text { tRNA } \\
\text { genes }\end{array}$ & $\begin{array}{c}\text { rRNA } \\
\text { operon }\end{array}$ \\
\hline Chromosome & $5,191,612$ & 38.2 & 5458 & 4055 & 121 & 11 \\
\hline pBMG1 & 169,684 & 34.2 & 162 & 104 & 2 & - \\
\hline pBMG2 & 122,563 & 33.7 & 83 & 32 & - & - \\
\hline pBMG3 & 157,203 & 33.8 & 175 & 100 & 5 & - \\
\hline pBMG4 & 139,476 & 33.6 & 128 & 64 & - & - \\
\hline pBMG5 & 87,511 & 35.1 & 100 & 37 & - & - \\
\hline pBMG6 & 105,079 & 33.7 & 109 & 63 & - & - \\
\hline pBMG7 & 75,956 & 33.5 & 72 & 42 & - & - \\
\hline pBMG8 & 70,948 & 35.1 & 91 & 47 & 17 & 1 \\
\hline pBMG9 & 45,372 & 35.5 & 66 & 31 & 18 & 1 \\
\hline
\end{tabular}

670

671

672

673

674

675

676

677

678

679

680

681

682

683

684

685

686

687 
Table 2: Concentration of metabolites produced during the mesotrione $(1 \mathrm{mM})$ degradation by $B$. megaterium Mes11 and fold change in NrfA2 expression. Values are expressed as means $(n=3) \pm$ standard error.

\begin{tabular}{|c|c|c|c|c|c|c|c|}
\hline Treatment & $\begin{array}{l}\text { Mesotrione } \\
(\mathrm{mM})\end{array}$ & $\begin{array}{l}\text { Hydroxylamino } \\
\text { derivative }(\mathrm{mM})\end{array}$ & $\begin{array}{l}\text { Isoxazolol } \\
(\mathrm{mM})\end{array}$ & AMBA (mM) & $\begin{array}{l}\text { Mass balance } \\
\text { (\% intitial dose) }\end{array}$ & $\begin{array}{l}\text { NfrA2 fold chan } \\
\text { (compared to cont }\end{array}$ & $\begin{array}{l}\text { nnege } \\
\text { trola }^{\mathrm{a}} \text { ) }\end{array}$ \\
\hline \multicolumn{8}{|r|}{693} \\
\hline Meso & $0.98 \pm 0.02$ & 0 & 0 & 0 & $100 \%$ & $1.44 \pm 0.34$ & \\
\hline Meso + Nico & $0.95 \pm 0.01$ & 0 & 0 & 0 & $100 \%$ & $1.77 \pm 0.78$ & 694 \\
\hline Meso + S-meto & $0.96 \pm 0.01$ & 0 & 0 & 0 & $100 \%$ & $1.46 \pm 0.69$ & \\
\hline $\mathrm{Meso}+\mathrm{Nico}+\mathrm{S}$-meto & $0.96 \pm 0.01$ & 0 & 0 & 0 & $100 \%$ & $1.30 \pm 0.38$ & 695 \\
\hline \multicolumn{7}{|l|}{ T2 } & 696 \\
\hline Meso & $0.63 \pm 0.05$ & $0.16 \pm 0.02$ & $0.14 \pm 0.03$ & 0 & $95 \%$ & $2.68 \pm 1.35$ & \\
\hline Meso + Nico & $0.56 \pm 0.02$ & $0.13 \pm 0.01$ & $0.11 \pm 0.02$ & $0.02 \pm 0.02$ & $86 \%$ & $4.02 \pm 1.02$ & 697 \\
\hline Meso + S-meto & $0.66 \pm 0.02$ & $0.10 \pm 0.01$ & $0.09 \pm 0.01$ & 0 & $89 \%$ & $14.69 \pm 0.49$ & \\
\hline $\mathrm{Meso}+\mathrm{Nico}+\mathrm{S}-\mathrm{meto}$ & $0.64 \pm 0.01$ & $0.10 \pm 0.00$ & $0.07 \pm 0.01$ & $0.02 \pm 0.02$ & $86 \%$ & $23 \pm 6.35$ & 698 \\
\hline \multicolumn{7}{|l|}{ T4 } & \multirow{6}{*}{$\begin{array}{l}699 \\
700\end{array}$} \\
\hline Meso & $0.09 \pm 0.00$ & $0.29 \pm 0.01$ & $0.41 \pm 0.10$ & $0.12 \pm 0.02$ & $93 \%$ & $8.64 \pm 2.32$ & \\
\hline Meso + Nico & $0.09 \pm 0.01$ & $0.24 \pm 0.02$ & $0.38 \pm 0.02$ & $0.17 \pm 0.02$ & $92 \%$ & $9.84 \pm 2.32$ & \\
\hline Meso + S-meto & $0.09 \pm 0.01$ & $0.22 \pm 0.01$ & $0.37 \pm 0.02$ & $0.20 \pm 0.02$ & $92 \%$ & $18.63 \pm 3.78$ & \\
\hline \multirow[t]{2}{*}{ Meso + Nico + S-meto } & $0.10 \pm 0.00$ & $0.19 \pm 0.00$ & $0.34 \pm 0.01$ & $0.22 \pm 0.01$ & \multirow[t]{2}{*}{$89 \%$} & $32 \pm 1.75$ & \\
\hline & & & & & & & \\
\hline \multicolumn{8}{|l|}{ T8 } \\
\hline Meso & 0 & $0.33 \pm 0.01$ & $0.53 \pm 0.01$ & $0.17 \pm 0.01$ & $105 \%$ & $5.71 \pm 0.19$ & \multirow{4}{*}{$\begin{array}{l}702 \\
703\end{array}$} \\
\hline Meso + Nico & 0 & $0.32 \pm 0.01$ & $0.49 \pm 0.00$ & $0.19 \pm 0.05$ & $105 \%$ & $6.58 \pm 0.53$ & \\
\hline Meso + S-meto & 0 & $0.25 \pm 0.00$ & $0.54 \pm 0.01$ & $0.25 \pm 0.01$ & $108 \%$ & $10.36 \pm 1.56$ & \\
\hline Meso + Nico + S-meto & 0 & $0.25 \pm 0.00$ & $0.53 \pm 0.00$ & $0.26 \pm 0.01$ & $108 \%$ & $7.24 \pm 0.86$ & \\
\hline
\end{tabular}

